Original Article

\title{
Night-day speed ratio of elephants as indicator of poaching levels
}

\author{
Festus W. Ihwagi ${ }^{\mathrm{a}, \mathrm{b}, *}$, Chris Thouless ${ }^{\mathrm{b}}$, Tiejun Wang ${ }^{\mathrm{a}, *}$, Andrew K. Skidmore ${ }^{\mathrm{a}}$, Patrick Omondi ${ }^{\mathrm{c}}$, \\ Iain Douglas-Hamilton ${ }^{\mathrm{b}, \mathrm{d}}$ \\ a Department of Natural Resources, Faculty of Geo-Information Science and Earth Observation (ITC), University of Twente, P.O. Box 217, 7500 AE, Enschede, The \\ Netherlands \\ b Save the Elephants, P.O. Box 54667-00200, Nairobi, Kenya \\ ${ }^{\mathrm{c}}$ Kenya Wildlife Service, P.O. Box 40241-00100, Nairobi, Kenya \\ d Department of Zoology, University of Oxford, Oxford, OX1 3PS, UK
}

\section{A R T I C L E I N F O}

\section{Keywords:}

African elephant

Poaching

Risk

GPS tracking

Night-day speed ratio

\begin{abstract}
A B S T R A C T
Poaching has escalated in recent years and is becoming the greatest immediate threat to elephants' survival. There is an urgent need to develop innovative and cost-effective methods for monitoring changes in elephant poaching levels remotely to complement the existing traditional field-based ground surveys. Since elephants are known to respond to anthropogenic risks by alterations in their speed of travel, we quantified this alteration as a ratio of night time speed to the day time speed (night-day speed ratio) and examined its relationship with poaching levels. Our hypothesis here is that poaching is a clear daytime risk, and thus an increase in night time movement rates over those seen during the day will support this hypothesis. Using elephant GPS tracking and mortality data collected in the Laikipia-Samburu ecosystem of northern Kenya between 2002 and 2012, we calculated the mean night-day speed ratio for collared elephants that utilised any of 13 contiguous land units, each under different ownership and management status, and related this ratio to the corresponding poaching levels before and during a poaching surge.

Our study shows that the mean night-day speed ratio of both male and female elephants did not vary significantly by month, ruling out possible seasonal effect. However, both male and female elephants moved more at night than during the day where and when poaching levels were high. The relationship between poaching levels and night-day speed ratios was stronger for females than for males. We concluded that the variation in the night-day speed ratio of elephants might be used as an effective indicator for changes poaching levels on a near real-time basis. We recommend its adoption as a complimentary anti-poaching tool, where GPS tracking data is already available, because it would increase the geographical range for monitoring of poaching levels. The significant alteration in movement behaviour by elephants in response to poaching also has potential implications for their foraging strategy, reproduction and ultimate survival, all of which are not yet fully understood.
\end{abstract}

\section{Introduction}

Killing for ivory has been a leading cause of the decline in the number of African elephants (Loxodonta africana Blumenbach, 1797) (Wittemyer et al., 2014). In the 1970s, a poaching surge led to widespread concern about the future of many elephant populations in Africa (Eltringham and Malpas, 1976; Douglas-Hamilton, 1980; Eltringham and Malpas, 1980; Douglas-Hamilton, 1988). Another poaching surge occurred across the African continent between 2010 and 2012, during which the rate of illegal killing of elephants exceeded the natural sustainability level (Wittemyer et al., 2014).

The Monitoring of Illegal Killing of Elephants (MIKE) programme, a programme of the Convention of the International Trade in Endangered Species (CITES), provides a framework for collecting information on elephant mortality based on a standardised protocol (MIKE, 2001). Designated intensive MIKE monitoring sites encompass only $40 \%$ of the African elephants' range (Nellemann et al., 2013). During the latest surge of poaching that peaked in the year 2011, an estimated 40,000 elephants were killed in these sites (indication potentially 100,000 elephants across their African range) leading to a catastrophic decline in key populations before poaching levels stabilised in the year 2013 (Wittemyer et al., 2014). A standard measure of the level of poaching in the MIKE sites, the Proportion of Illegally Killed Elephants (PIKE), has been adopted by the Secretariat of CITES (Kahindi et al., 2010;

\footnotetext{
* Corresponding authors at: Department of Natural Resources, Faculty of Geo-Information Science and Earth Observation (ITC), University of Twente, P.O. Box 217, 7500 AE, Enschede, The Netherlands
}

E-mail addresses: ihwagi@gmail.com (F.W. Ihwagi), t.wang@utwente.nl (T. Wang). 
Jachmann, 2013). An elephant population with a PIKE value of over $54 \%$ has a high probability of declining, as there are insufficient births to compensate for the number of deaths (Wittemyer et al., 2014). Poaching levels in Africa have been on the decline since the year 2011, but they are still above the naturally sustainable level of 54\% PIKE (https://cites.org/sites/default/files/eng/prog/MIKE/MIKE_report_ released_WWD_3Mar2017.pdf: accessed 21 march 2017). Since elephant poaching remains rampant, there is an urgent need to develop innovative near real-time but cost-effective methods for monitoring poaching beyond the traditional ground-based time-consuming patrols, which are often restricted to designated sites (O'Donoghue and Rutz, 2016).

A male elephant, recently collared in Tana River, a different ecosystem in South Eastern Kenya near the highly insecure Somali border, became more nocturnal as he approached and moved into less secure areas (Douglas-Hamilton pers. comm 2016). This led us to consider whether variation in movement rates between day and night times by elephants in risky areas is a general phenomenon and we sought to analyse existing data. Exploratory data analyses (EDA) is an established tradition in statistics that offers computational and conceptual framework to foster hypothesis development (Tukey, 1977; Behrens, 1997). EDA encompasses the understanding of patterns in existing data. Elephants are intelligent social beings able to perceive loss of the life of conspecifics and react to the presence of potentially threatening human beings (Douglas-Hamilton et al., 2006; Bates et al., 2008; Hart et al., 2008). Elephants avoid encroaching human settlements that present a risk of conflict and human related mortality during the day (Galanti et al., 2006; Graham et al., 2009; Boettiger et al., 2011). In fragmented ecosystems, elephants have distinct home ranges connected by travel corridors along which they move faster in response to prevailing danger (Douglas-Hamilton et al., 2005). They also increase their speed when crossing busy roads (Blake et al., 2008). Since most encounters with humans, including poachers, occur in the daytime and elephants are intelligent, it would make sense for them to become more nocturnal when they are under threat as has been observed in studies on elephant movement behaviour at the interface between farming and ranching communites (Graham et al., 2009).

In ecology, some species threatened by predation are known to respond in a graded way that corresponds to the degree, magnitude and temporal scale of the threat posed (Helfman, 1989; Levin, 1992; Kitchen et al., 2000; Creel et al., 2005; Fischhoff et al., 2007; SanchezMercado et al., 2008; Chittka et al., 2009). Experiments regarding the day-night behaviour of coyotes (Canis latrans Say, 1823), showed that their diurnal activity increased after exploitation by humans ceased. Plains zebras (Equus burchelli Gray, 1924) have been observed to walk faster at night time in areas where they risked predation by lions (Panthera leo Linnaeus, 1758). Poaching is the greatest immediate threat to elephants' survival (Nellemann et al., 2013). Understanding how elephants alter their movement behaviour during the day and night under the threat of poaching is a step towards understanding how they adapt to short-term threat. Since elephants are known to respond to anthropogenic risks by alterations in their speed of travel (DouglasHamilton et al., 2005; Blake et al., 2008; Graham et al., 2009), we examined the relationship between day-night movement rates and mortality risks due to poaching. Our hypothesis here is that the daynight movement rates are a predictor of poaching threat. To test this hypothesis, we sought to determine the following:

(1) Are there significant differences in the mean night-day speed ratio of elephants over time (within the months and between the low and high poaching periods)?

(2) Is there a significant relationship between the night-day speed ratio of elephants and prevailing poaching levels?

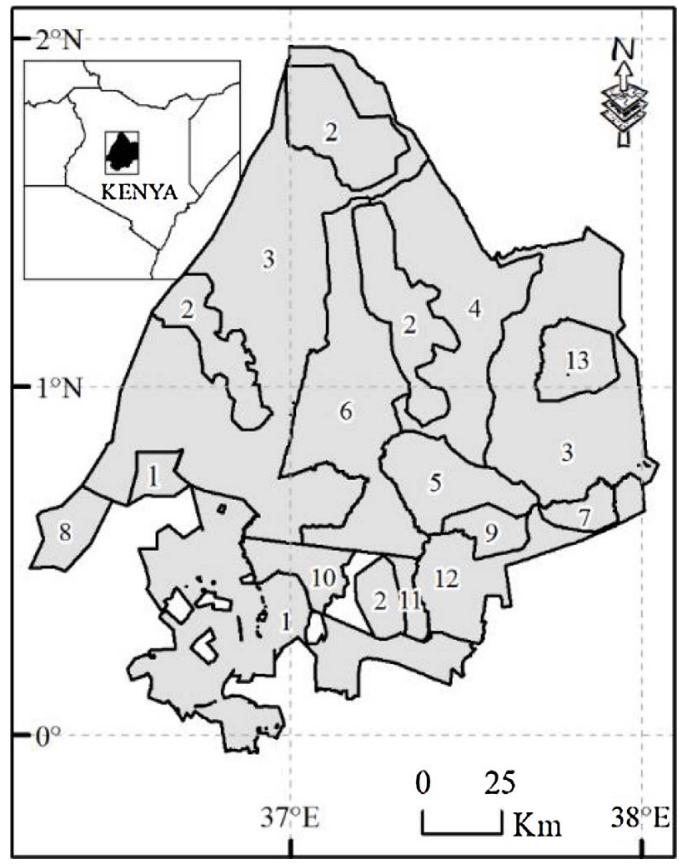

Fig. 1. Location of the Laikipia-Samburu ecosystem in northern Kenya. The land units used for site aggregation of mortality data are assigned generalised names. These are: (1) Laikipia Private Ranches, (2) Forest Reserves, (3) Waso-Baragoi, (4) Wamba EastNamunyak, (5) West Gate-Kalama, (6) Kipsing-Meibae, (7) Shaba National Reserve, (8) Laikipia Nature Conservancy, (9) Samburu and Buffalo Springs National Reserves, (10) Naibunga, (11) Lekuruki-Ilngwezi, (12) Isiolo West, and (13) Sera.

\section{Materials and methods}

\subsection{Study area}

To test our hypothesis, we needed a study site with sufficient elephant GPS tracking data, as well as ground-verified elephant mortality records for the same period. The Laikipia-Samburu ecosystem in northern Kenya meets these criteria as it is home to a long-term elephant tracking programme (Wittemyer et al., 2005a, 2005b). As a designated MIKE site, the ecosystem has a consistent dataset detailing causes of elephant mortality (Kahindi et al., 2010). The ecosystem encompasses different land units, which encounter varying levels of poaching (Ihwagi et al., 2015), thus presenting an ideal poaching gradient for testing the hypothesis.

The Laikipia-Samburu ecosystem lies within the coordinates $0^{\circ}$ and $2^{\circ} \mathrm{N}$, and $36.2^{\circ} \mathrm{E}$ and $38.3^{\circ} \mathrm{E}$ (Fig. 1). The area experiences highly variable bimodal rainfall with peaks in May and November and yearly totals ranging from below $400 \mathrm{~mm}$ towards the north to a maximum of $600 \mathrm{~mm}$ in the south (Barkham and Rainy, 1976; Ihwagi et al., 2012). There were an estimated 6000 elephants in the ecosystem during the study period (Thouless et al., 2008; Ihwagi et al., 2015). Reports of elephant mortality from different small land holdings are aggregated into larger contiguous land units in order to collate enough sample sizes to reliably calculate the proportion of illegally killed elephants (Douglas-Hamilton et al., 2010).

\subsection{GPS tracking data and calculation of night-day speed ratio of elephants}

Unlike male African elephants, who are usually solitary, female African elephants live in matrilineal families that can have as many as 36 members (Wittemyer, 2001; Wittemyer et al., 2005a,b). Only one individual elephant was tracked per family unit. The collars used were sourced from either African Wildlife Tracking (AWT) from South Africa (www.awt.co.za), Savannah Tracking (http://www.savannahtracking. $\mathrm{com} /$ ), or FOLLOWIT (www.followit.se) from Sweden. The collars 
comprised the following models: Lotek 1000, Lotek 2000, TVP Simplex, AWT GSM, AWT SAT, AWT GSM, Savannah Tracking, Argos and TVP Sat. The different types of GPS collars are comparable in their performance regarding the acquisition of locations, though their lifespan may vary (Pastorini et al., 2015). The choice of collar is thus influenced by their technical specifications, the environment they are deployed in and their cost. The collars were programmed to record and transmit their location every hour.

The elephants were tracked for varying lengths of time ranging from a few months to over three years per individual. The tracking data were filtered for erroneous points due to occasional GPS errors using a biologically defined upper movement limit of $7 \mathrm{~km} / \mathrm{h}$ (Wall et al., 2013). The data were projected on the Universal Transverse Mercator (UTM) WGS-84 reference system. Elephants exhibit non-usual movement patterns at the edge of their range, either aggregating at fences (Vanak et al., 2010) or crossing roads fast (Blake et al., 2008). In order to focus on responses to possible poaching risk rather than other clear anthropogenic risks, we excluded the areas $2.5 \mathrm{~km}$ from roads or fences. The Animal Movement Ecology Tools (ArcMET) (Wall et al., 2014) for ArcGIS 10.2.1 (ESRI 2014) were used to calculate the hourly speeds between the successive GPS points.

The study area lies on the equator and as such, there is no variation in day length throughout the year. The GPS locations for night and day were separated by the cut off times 6:00 AM and 6:00 PM local time $(\mathrm{GMT}+3)$. The night-day speed ratio of the elephants in each land unit was calculated as the mean hourly night time speed divided by the mean hourly daytime speed for the entire period an elephant was in each land unit before and/or during the poaching surge. An added advantage of aggregating data into a longer tracking period is that it gives time for a reasonable sample size of dead elephants to be recorded since PIKE is a measure of proportionate cause of death (DouglasHamilton et al., 2010). The value "1" for the night-day speed ratio of the elephants thus corresponds to equal mean night and mean day speeds. As the elephants move more at night, the night-day speed ratio increases and vice versa. In the year 2009, a severe drought affected the ecosystem (Wittemyer et al., 2013). The year 2009 was therefore omitted from the analyses, because the elephants were most likely responding to the unusual drought-related environmental stress, which would potentially mask the effect of poaching, our primary concern. The period between 2010 and 2012 was characterised by high poaching levels in the ecosystem (Ihwagi et al., 2015). Therefore, we defined two broad study periods based on the prevailing poaching levels; before (2002-2008) and during (2010-2012) the poaching crisis. Fig. 2 shows the average night-day speed ratio of all elephants tracked within each land unit before and during the poaching crisis.

\subsection{Collecting mortality data and calculation of the proportion of illegally killed elephants (PIKE)}

A participatory approach involving the key government agency (Kenya Wildlife Service), pastoral herders, researchers, community conservancy managers and ranchers has been established to gather information on the elephant mortality in the area (Kahindi et al., 2010). Particulars of each dead elephant encountered including the estimated date of death, GPS coordinates, local area name, and cause of death (if ascertainable) were collected, as per the standard protocol developed by the Technical Advisory Group (TAG) of the MIKE programme (CITES. Secretariat, 1999). Four categories of death were recognised, i.e. illegal killing, problem animal control by authorised personnel in defence of either life or property, and natural mortality. Where it was not possible to identify the cause of death with certainty, the cause of death was marked as 'unknown.' The Proportion of Illegally Killed Elephants (PIKE) out of all mortality cases has been adopted by CITES as a measure of the severity of poaching at a given space or time (Douglas-Hamilton et al., 2010; Jachmann, 2013; Nellemann et al., 2013). It has been established that there are significant differences in
PIKE values between various land units in the ecosystem (Ihwagi et al., 2015).

A total of 1156 elephant carcases was reported and verified between 2002 and 2012 (Table 1). Fig. 3 shows their locations and whether the elephants were illegally killed or otherwise. Approximately $15 \%$ of the carcasses that had an erroneously transcribed GPS were assigned to a land unit based on the name of the local area. The mean PIKE value for each land unit during both the pre-poaching period (2002-2008) and the poaching surge period (2010-2012), was calculated (Fig. 4a and b).

\subsection{Elephant utilization units for testing spatial differences in the night-day speed ratio}

To be able to compare the variation in night-day speed ratio of the elephants with the PIKE data for the land units defined by DouglasHamilton et al. (2010), movement data of 32 elephants (15 males and 17 females) tracked for at least one year, and which visited more than one land unit were used. We stipulated the minimum tracking period of one-year, because an elephant might by then have walked throughout its full potential range, driven by seasonal variations in resource availability (i.e., through wet and dry seasons). Because elephants utilised multiple land units, this ensured that the areas encompassed a gradient in poaching risk, which was our primary interest. For each elephant, we calculated its average night-day ratio in each land unit, separating the elephants into two groups: those tracked before and those tracked during the poaching surge. the decision was arrived at because there were no monthly (seasonal) differences, but there were differences between the periods "before" and "during" the poaching surge (see results section).

\subsection{Statistical analyses}

Statistical analyses were performed using R ( R Development Core Team, 2012). All tests were carried at significance level of 0.05 . To test if there were significant monthly (seasonal) variations in the night day speed ratio of elephants over the entire study period, we used ANOVA and only performed this test using data from 2002 to 2008 (prepoaching crisis) for all available data (60 elephants). For this test, it did not matter how many months elephant had been tracked for. We used the Student's Two Sample $t$-Test to determine whether there were significant differences in the night-day speed ratio of elephants in low poaching areas (PIKE $<54 \%$ ) and high poaching areas (PIKE $\geq 54 \%$ ).

Some elephants had more data (sampling rates) than others and it was important to determine if including elephant identity (ID) as a random factor in a model was warranted. To achieve this, two linear mixed effect models implemented with package "lme4" were created; one with all covariates (average travel speed, area name, sex, proportion of illegally killed elephants (PIKE) and the real elephant ID and another model with a constant elephant ID (Galwey 2007). A value of "1" was allocated for each elephant ID), but to achieve a grouping level necessary to execute the model, one elephant ID was entered as " 0.999 "; a value very close to " 1 " thus with no likelihood of being significantly different from " 1 ". The response variable in both models was the ratio of night-day time speed of each elephant for all the period it moved in a given land unit before and/or during the poaching surge. PIKE was factored in the model as a continuous variable ranging from $0 \%$ to $100 \%$. The two models were compared using ANOVA to check for the one with lowest AIC and BIC. Since it was not necessary to include ID as a random factor (see results section), we proceeded to model the variation in night-day speed ratio of elephants with PIKE, speed and sex using a linear model. Models with different combinations of covariates and their interactions were fitted and compared using the second-order Akaike's Information Criterion (AICc) (Burnham and Anderson 2002). 


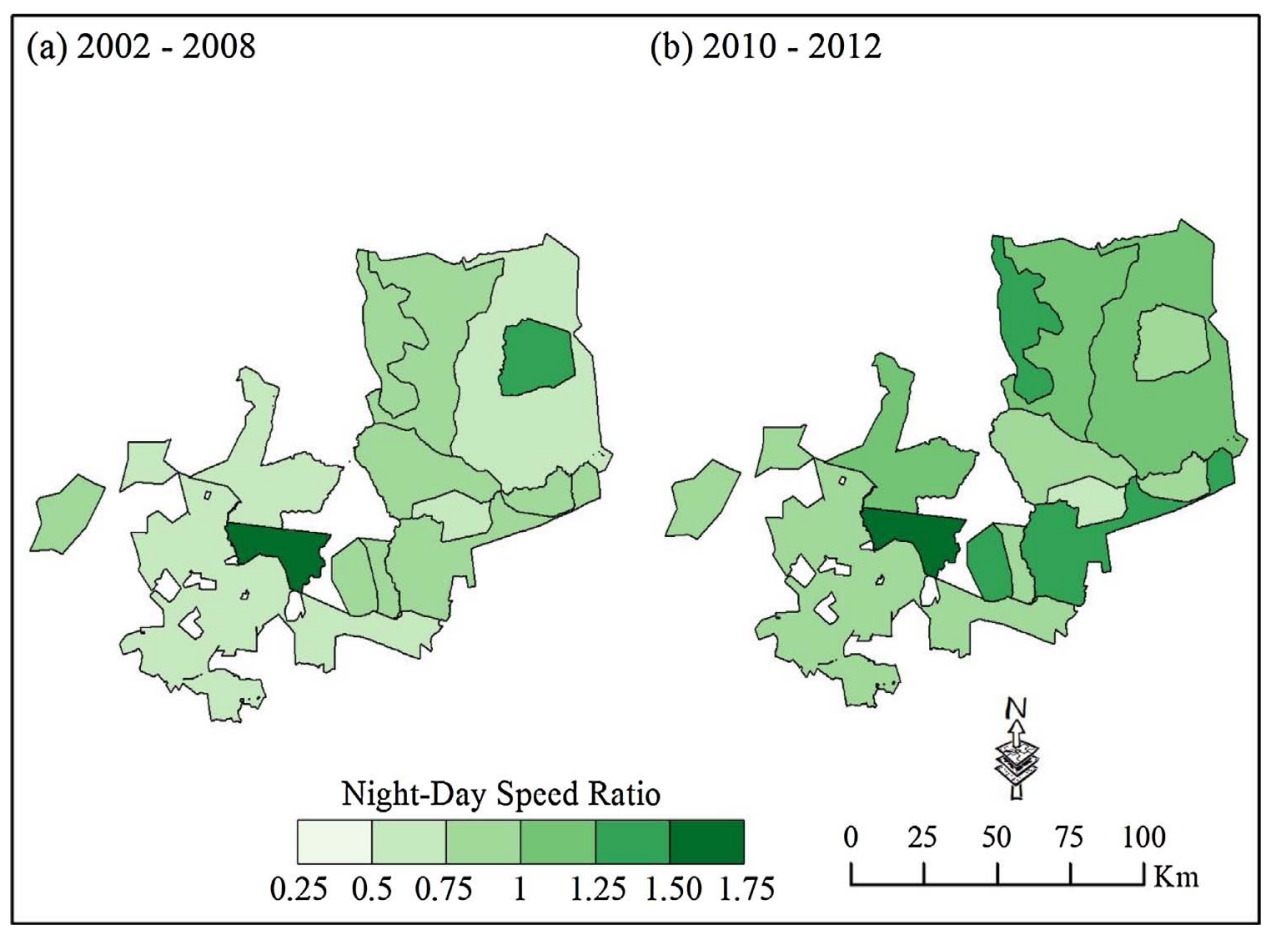

Fig. 2. The mean night-day speed ratio of all elephants tracked in the different land units in LaikipiaSamburu ecosystem from (a) 2002-2008 and (b) 2010-2012.
Table 1

The number of dead elephants from various causes and the proportion of illegally killed elephants (PIKE) in various land units.

\begin{tabular}{|c|c|c|c|}
\hline Time period & Land unit name & $\begin{array}{l}\text { Number of dead } \\
\text { elephants (n) }\end{array}$ & $\begin{array}{l}\text { Proportion of } \\
\text { illegally killed } \\
\text { elephants (PIKE) }\end{array}$ \\
\hline 2002-2008 & Baragoi - Waso & 192 & $49.0 \%$ \\
\hline 2002-2008 & Forest Reserve & 194 & $53.6 \%$ \\
\hline $2002-2008$ & $\begin{array}{l}\text { Koija Community } \\
\text { Ranches }\end{array}$ & 32 & $62.5 \%$ \\
\hline 2002-2008 & $\begin{array}{l}\text { Laikipia Nature } \\
\text { Conservancy }\end{array}$ & 107 & $52.3 \%$ \\
\hline 2002-2008 & Laikipia Private Ranches & 186 & $19.9 \%$ \\
\hline 2002-2008 & Lekuruki \& Il-Ngwezi & 46 & $32.6 \%$ \\
\hline 2002-2008 & $\begin{array}{l}\text { Nakuprat, } \\
\text { Nasuulu \& Leparua }\end{array}$ & 56 & $48.2 \%$ \\
\hline 2002-2008 & $\begin{array}{l}\text { Samburu-Buffalo } \\
\text { Springs NRs }\end{array}$ & 26 & $11.5 \%$ \\
\hline $2002-2008$ & Sera & 26 & $80.8 \%$ \\
\hline $2002-2008$ & Shaba National Reserve & 27 & $51.9 \%$ \\
\hline $2002-2008$ & Wamba East- Namunyak & 91 & $35.2 \%$ \\
\hline 2002-2008 & Westgate - Kalama & 27 & $25.9 \%$ \\
\hline 2010-2012 & Baragoi-Waso & 117 & $54.7 \%$ \\
\hline 2010-2012 & Forest Reserve & 108 & $64.8 \%$ \\
\hline 2010-2012 & $\begin{array}{l}\text { Kipsing-Meibae } \\
\text { Conservancies }\end{array}$ & 64 & $50.0 \%$ \\
\hline 2010-2012 & $\begin{array}{l}\text { Laikipia Nature } \\
\text { Conservancy }\end{array}$ & 73 & $52.1 \%$ \\
\hline 2010-2012 & Laikipia Private Ranches & 274 & $47.8 \%$ \\
\hline 2010-2012 & $\begin{array}{l}\text { Nakuprat, } \\
\text { Nasuulu \& Leparua }\end{array}$ & 132 & $76.5 \%$ \\
\hline 2010-2012 & $\begin{array}{l}\text { Samburu-Buffalo } \\
\text { Springs NRs }\end{array}$ & 74 & $20.5 \%$ \\
\hline 2010-2012 & Sera & 13 & $30.8 \%$ \\
\hline 2010-2012 & $\begin{array}{l}\text { Westgate-Kalama } \\
\text { Conservancies }\end{array}$ & 45 & $28.9 \%$ \\
\hline
\end{tabular}

\section{Results}

3.1. Variation in night day speed ratio of elephants in laikipia-Samburu ecosystem between months and between low and high poaching periods

Twenty eight females and 32 males were tracked for a cumulative

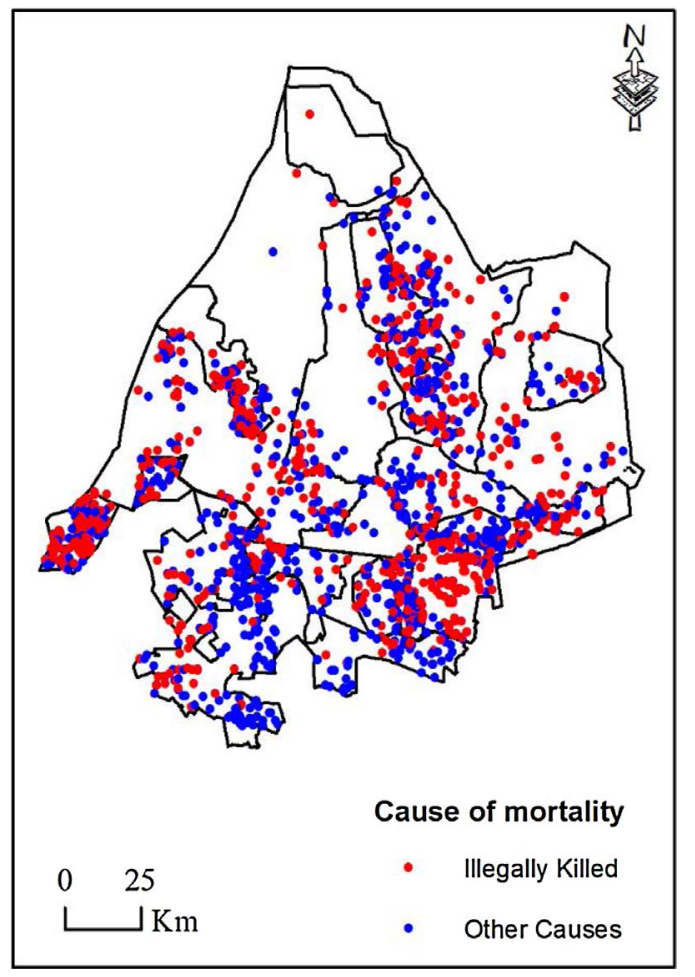

Fig. 3. The distribution of elephant carcases recorded from 2002 to 2012 (excluding year 2009) in the Laikipia-Samburu ecosystem and the main causes of death of the elephants.

total of 72 and 118 months respectively. There were no significant monthly variation of the mean day-night speed ratio of either female $(F$ $11,60=1.06, P=0.41)$ or male $\left(F_{11,107}=1.72, P=0.09\right)$ elephants tracked within the same time period with respect to the onset of poaching surge. We compiled a total of 79 elephant utilization units, i.e., summaries of individual elephant into all land units it visited during the entire study period; 31 for male elephants (18 before and 13 during poaching surge) and 48 for female elephants (33 before and 18 


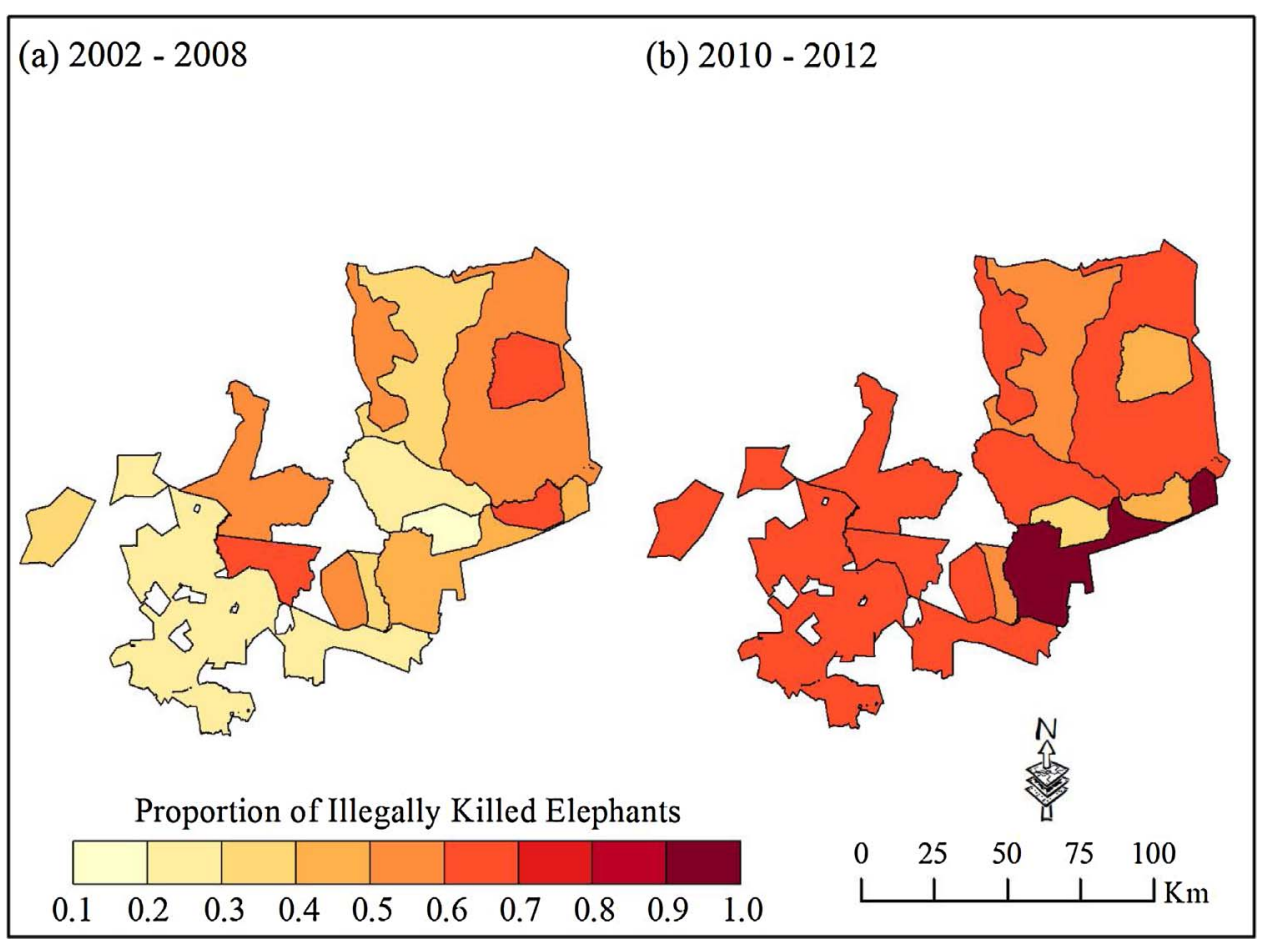

Fig. 4. The mean annual Proportion of Illegally Killed Elephants (PIKE) in the different land units within the Laikipia-Samburu ecosystem (a) before the poaching surge (2002-2008) and (b) during the poaching surge (2010-2012).

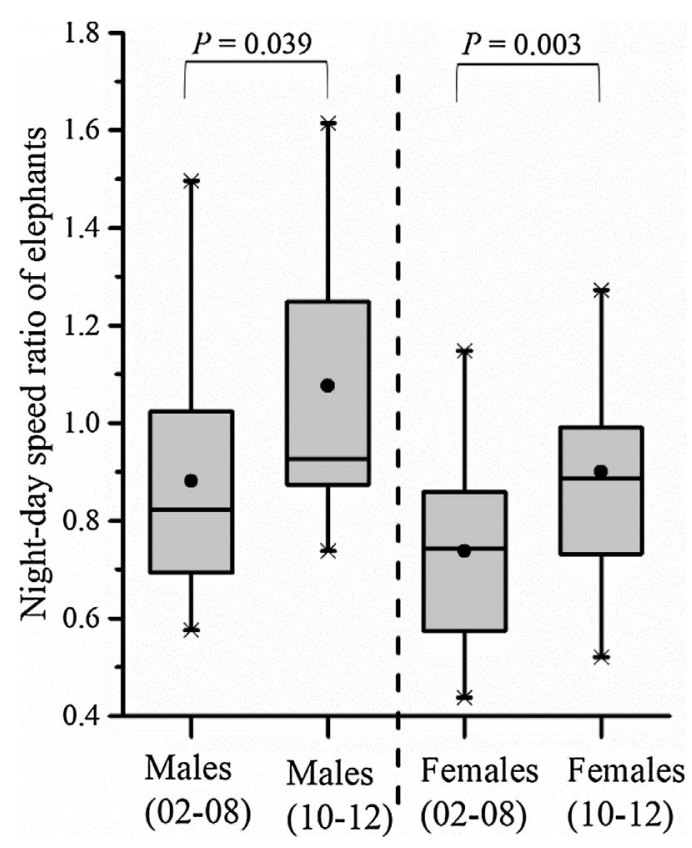

Fig. 5. Box plots show the average night-day speed ratio of male and female elephants in the Laikipia-Samburu ecosystem before (the years 2002-2008) and during (the 2010-2012) the poaching surge. There was a significant increase in the night-day speed ratio of both male and females elephants.

during the poaching surge). We tested for the normality of the data for males and females separately using Shapiro-Wilk's test. The data for females was normally distributed (Shapiro-Wilk test: $W=0.953$, $P=0.051$ ), but that of males was not normally distributed (ShapiroWilk test: $W=0.896, P=0.006$ ). Using Mann-Whitney test for the male elephants, and an independent samples paired $t$-test for the female elephants, we tested for the differences in night day speed ratio for the male elephants between the period 2002-2008 (before poaching surge) and the period 2010-2012 (during poaching surge). There was a significant difference in the night-day speed ratio of elephants for the males (Males: Mann-Whitney test: $U=169, P=0.039, \mathrm{n}=32$ ) and the females (t-test: $t=3.286, P=0.003, \mathrm{n}=48$ ) (Fig. 5).

3.2. Modelling the variation in night-day seed ratio of elephants with the proportion of illegal killing, elephant travelling speed and sex using a linear model

Two linear mixed effects models one with a full set of covariates and elephant ID and another with constant ID were compared using ANOVA (Table 2.). The model with constant elephant ID had lower AIC and BIC values (Table 3 ). This showed that there was no significant contribution by the elephant ID when factored as a random effect in a model.

A set of multiple linear regression models with different combinations of covariates were Constructed (Table 4).

The top two models with were identified by weighting the secondorder AIC (AICc) (Table 5). The top model featured PIKE and sex. Evidence ratio between models 'PIKE + sex' and 'PIKE + sex + speed' was 3.13. The coefficients of the top are shown in Table 6. Using ANOVA, we tested for the significance of the results of the top model featuring "PIKE" and "Sex". The top model was statistically significant in explaining the variation in the night-day speed ratio of elephants $\left(F=47.92, R^{2}=0.558, P<0.001, D F=76\right)$.

\section{Discussion}

The night-day speed ratio of elephants increases significantly with the increase in poaching levels, which suggests that elephant movement

Table 2

Two linear mixed effects models constructed for the assessment of the significance analyses of elephant identity as a random effect covariate in modelling the variation of the night-day speed ratio (NDR) of elephants. One model has real elephant identify while the other one has constant elephant identity. The constant identity used was ' 1 ' but one entry was assigned " 0.99 " to offer the required grouping level for executing the model.

\begin{tabular}{ll}
\hline Model & Model description \\
\hline Model lmer1 & lmer(NDR $\sim$ PIKE + sex + speed + (1 | real elephant ID), data) \\
Model lmer2 & $\begin{array}{l}\text { lmer(NDR } \sim \text { PIKE }+ \text { sex }+ \text { speed }+(1 \mid \text { constant elephant ID), } \\
\text { data })\end{array}$ \\
\hline
\end{tabular}


Table 3

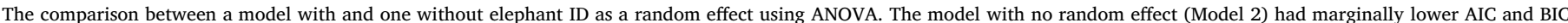
values.

\begin{tabular}{|c|c|c|c|c|c|c|c|c|}
\hline Model & Df & AIC & BIC & logLik & deviance & Chisq & Df & $\operatorname{Pr}(>$ Chisq $)$ \\
\hline Model lmer1 & 6 & -54.872 & -40.655 & 33.436 & -66.872 & & & \\
\hline Model lmer2 & 6 & -54.868 & -40.652 & 33.434 & -66.868 & 0 & 0 & 1 \\
\hline
\end{tabular}

Table 4

Candidate models in the analyses of the relationship between the night-day speed ratio (NDR) of elephants, the proportion of illegally killed elephants (PIKE), sex, mean travel speed in a linear model. The Asterisk between covariates shows interactive effects of the covariates.

\begin{tabular}{ll}
\hline Model & Model description \\
\hline 1 & NDR $=\beta_{0}+\beta_{1}$ (PIKE) $+\beta_{2}$ (sex $+\beta_{3}$ (speed) \\
2 & NDR $=\beta_{0}+\beta_{1}$ (PIKE) $+\beta_{2}$ (sex $*$ speed $)$ \\
3 & NDR $=\beta_{0}+\beta_{1}$ (PIKE) $+\beta_{2}$ (speed) \\
4 & NDR $=\beta_{0}+\beta_{1}$ (sex $+\beta_{2}$ (speed $)$ \\
5 & NDR $=\beta_{0}+\beta_{1}$ (speed) \\
6 & NDR $=\beta_{0}+\beta_{1}$ (PIKE) \\
7 & NDR $=\beta_{0}+\beta_{1}$ (PIKE) $+\beta_{2}$ (sex $)$ \\
\hline
\end{tabular}

Table 5

Selection statistics for the top two models for the analyses of relationships between the night-day speed ratio (NDR) of elephants, the proportion of illegally killed elephants (PIKE), sex, land unit and mean travel speed. AICc denotes the second order Akaike's Information criterion, $\triangle \mathrm{AICc}$ denotes Delta AICc which is the difference between the model's AICc and the lowest of all the AICc values, and AICcWt denotes Akaike weights.

\begin{tabular}{llll}
\hline Model & AICc & $\Delta$ AICc & AICcWt \\
\hline PIKE + sex & -79.25 & 0.00 & 0.69 \\
PIKE + sex + speed & -76.97 & 2.28 & 0.22 \\
\hline
\end{tabular}

\section{Table 6}

The coefficients of the covariates of the top model of night day speed ratio of elephants as a function of the Proportion of Illegally Killed Elephants (PIKE) and their statistical significance. The model was statistically significant in explaining the variation in the nightday speed ratio of elephants $\left(F=47.92, R^{2}=0.558, P<0.001, D F=76\right.$ ).

\begin{tabular}{lllll}
\hline & Estimate & Standard Error & t value & Significance (P) \\
\hline Intercept & 0.4165 & 0.0849 & 4.907 & 0.000 \\
PIKE & 0.0078 & 0.0009 & 8.555 & 0.000 \\
Sex & 0.1332 & 0.0400 & 3.328 & 0.000 \\
\hline
\end{tabular}

behaviour could be used as a reliable indicator of changes in the level of poaching risk. As changes in poaching levels cannot be determined instantly from field-verified carcass records, this result offers a potential indicator for changes poaching levels in near real-time using GPS tracking data. For example, elephants in the Sera Conservancy, which experienced declining poaching levels even as the levels in the rest of the ecosystem increased, exhibited a proportionately lower night-day speed ratio. This isolated case of a decrease in poaching levels against the general trend in the ecosystem has been attributed to improved conservation efforts by local communities (Ihwagi et al., 2015), and thus forms a constructive test case for the hypothesis.

The results from GPS tracking data and intensive field monitoring of causes of elephant mortalities are congruent with historical visual field based observations and notes to the effect that elephants in low poaching environments are more active during the day than at night (Wyatt and Eltringham, 1974; Douglas-Hamilton, 1998a). This study offers in innovative approach that quantifies the change in elephant movement rates between night time and day time using GPS tracking technology, as an indicator of poaching levels. The increased night time activity of elephants encountering heightened poaching levels suggests that poaching activities in the study area occur mainly during the day.
The night-day speed ratio of elephants can potentially be applied in many ecosystems, where it is a measure of change in movement rates from a previously observed pattern. In this study, we were not able to establish a baseline activity pattern, i.e., night-day ratio under zero poaching risk, because poaching was prevalent in all land units. We recommend the establishment of a baseline night-day ratio of activity in different environments and seasons (in other elephant populations further from the equator, more seasonal variation may exist).

The lack of seasonal variation in night-day speed ratio of elephants in an environment with seasonal rainfall fluctuations (and presumably changes in forage availability) suggests that their diel movement behaviour is in response to a variable of much shorter timescale, like poaching. This view is corroborated by past findings that seasonal variation in the availability of a natural resource is not expected to result in diurnal movement behaviour of an animal (Godvik et al., 2009). Nevertheless, there might be a need to factor the role of seasonality in, when inferring the level of poaching using night-day speed ratios of elephants inhabiting ecosystems with clearly defined seasons, or with extreme diurnal variation in weather elements such as temperature, as can be expected farther away from the equator. A key challenge in replicating this study in other sites is access to the detailed site level data on mortality locations within sites. The numbers of dead elephants found for each MIKE site are on the website of CITES; https:// fusiontables.google.com/DataSource?docid = 1juiqNCOUwqperYcoq_ uCWaZ5lEs8t09hfRry_I37\#rows:id = 4 (Accessed on 24th November 2016). The details of elephant carcases within sites are owned by the range States that provided them. We worked with the only dataset that we could access with permission from the Government of Kenya, which is coincidentally the most comprehensive of all reporting sites across Africa. We recommend testing of this new indicator of poaching in places where individual-elephant mortality records can be accessed with permission from the respective governments.

\subsection{Implications and conclusions}

The significant alteration of movement behaviour by elephants in response to poaching risk has potential implications for their foraging strategy, their reproduction, and their ultimate survival, all of which are not yet fully understood. The risk of predation often leads prey species to make use of less good foraging locations (Hamel and Côté, 2007). Reproduction and survival of mammals depend on the cumulative effects of movement behaviour (Powell and Mitchell, 2012). Besides the potential reduction in foraging efficiency, foraging under the cover of darkness might expose elephant calves to predation from lions, which are primarily nocturnal.

We illustrated that GPS tracking data can be used as an antipoaching tool. The night-day speed ratio can potentially be applied to elephants in diverse ecosystems, because it is a relative measure of change in movement behaviour based on a previously observed movement pattern. An advantage is that the tracking dataset across the African elephant range is rapidly increasing (Douglas-Hamilton, 1998b; Douglas-Hamilton et al., 2005; Blake et al., 2008; Wall et al., 2013). This presents an ideal opportunity to assess elephant movement behaviour under risk of poaching using remote sensing data. Application of the night-day speed ratio as a standard metric would enable utilization of the existing tracking datasets across the elephant range as a poaching monitoring tool, especially outside designated MIKE sites. The 
approach proposed in this study is not a replacement for the MIKE programme, but a complementary method that can aid wildlife managers and researchers in filling knowledge gaps on risk levels across the elephant range.

\section{Data accessibility}

The access to the elephant tracking and mortality sites is restricted to safeguard the safety of elephants, which are endangered.

\section{Author contribution}

FI, CT, AS, TW, and ID conceived the idea and designed the methodology; FI, ID and PO collected the data; FI, CT, TW, ID and AS analysed the data; FI, CT, TW, AS and ID wrote the paper: All authors contributed critically to the drafts and gave final approval for publication.

\section{Acknowledgements}

We thank the Government of Kenya through the Kenya Wildlife Service (KWS) for making the mortality data available for this study and publication. The long-term elephant tracking programme under the auspices of Save the Elephants (www.savetheelephants.org) has been supported in part by different organisations, including Safaricom Foundation, JRS Biodiversity Foundation, The Nature Conservancy and Kenya Wildlife Service. We thank Albertus Toxopeus for comments during the preparation of the manuscript. The research was conducted with support, extended directly to the first author, from the Netherlands Fellowship Programme (NFP-PhD.14/44) and the Wildlife Conservation Network. The financiers had no role in design implementation, writing or publication of this manuscript. We thank the ESRI Conservation Program (ECP) for the provision of ArcGIS software.

\section{References}

Barkham, J.P., Rainy, M.E., 1976. The vegetation of the Samburu-Isiolo Game Reserve. Afr. Wildl. J. 14, 297-329.

Bates, L.A., Sayialel, K.N., Njiraini, N.W., Moss, C.J., Poole, J.H., Byrne, R.W., 2008. Elephants classify human ethnic groups by odor and garment color. Curr. Biol. 17, 1938-1942.

Behrens, J.T., 1997. Principles and procedures of exploratory data analysis. Psychol. Methods 2, 131-160.

Blake, S., Deem, S.L., Strindberg, S., Maisels, F., Momont, L., Isia, I.-B., Douglas-Hamilton, I., Karesh, W.B., Kock, M.D., 2008. Roadless wilderness area determines forest elephant movements in the Congo basin. PLoS One 3, e3546.

Boettiger, A.N., Wittemyer, G., Starfield, R., Volrath, F., Douglas-Hamilton, I., Getz, W.M., 2011. Inferring ecological and behavioral drivers of African elephant movement using a linear filtering approach. Ecology 92, 1648-1657.

Burnham, K.P., Anderson, D.R., 2002. Model Selection and Multimodel Inference: a Practical Information Theoretic Approach, 2nd ed. Springer-Verlag, New York.

CITES. Secretariat, 1999. Trade in elephant specimens [Conf 10.10]. In: CITES Proceedings of the Tenth Meeting of the Conference of the Parties of the Convention on International Trade in Endangered Species of Wild Fauna and Flora, Harare, Zimbabwe, 9 to 20 June, 1997, pp. p76-78; Annexes. CITES. Secretariat, Geneva.

Chittka, L., Skorupski, P., Raine, N.E., 2009. Speed-accuracy tradeoffs in animal decision making. Trends Ecol. Evol. 24, 400-407.

Creel, S., Winnie, J., Maxwell, B., Hamlin, K., Creel, M., 2005. Elk alter habitat selection as an antipredator response to wolves. Ecology 86, 3387-3397.

Douglas-Hamilton, I., Krink, T., Vollrath, F., 2005. Movements and corridors of African elephants in relation to protected areas. Naturwissenschaften 92, 158-163.

Douglas-Hamilton, I., Bhalla, S., Wittemyer, G., Vollrath, F., 2006. Behavioural reactions of elephants towards a dying and deceased matriarch. Appl. Anim. Behav. Sci. 100, 87-102.

Douglas-Hamilton, I., Wittemyer, G., Ihwagi, F., 2010. Levels of illegal killing of elephants in the Laikipia-Samburu MIKE site. A Report for the Convention on International Trade in Endangered Species (CITES) CoP 15 (40.1), 1-14. Doha, Qatar. Available: https://cites.org/common/cop/15/inf/E15i-40.pdf Accessed 21 August 2017.

Douglas-Hamilton, I., 1980. Elephant numbers are falling heavily. IUCN Bull. 11, 2-3 8-9; table; photos.

Douglas-Hamilton, I., 1988. The great east african elephant disaster. Swara 11, 8-11 (tables;figs).

Douglas-Hamilton, I., 1998a. Tracking African elephants with a global positioning system (GPS) radio collar. [Paper presented at Current Issues Session, AfESG meeting Ouagadougou, Burkina Faso, 26-31 January, 1998]. Pachyderm 81-92 (tables;figs;maps;refs).

Douglas-Hamilton, I., 1998b. Tracking elephants using GPS technology. Pachyderm 25, 81-92.

ESRI, 2014. Environmental Systems Research Institute Inc. Arc View Spatial Analyst, Version 3.2a. ESRI, Redlands, CA, USA.

Eltringham, S.K., Malpas, R.C., 1976. Elephant slaughter in Uganda. ORYX 13, 334-335.

Eltringham, S.K., Malpas, R.C., 1980. The decline of elephant numbers in Rwenzori and Kabalega Falls National parks, Uganda. Afr. J. Ecol. 18, 73-86 (tables;figs;maps;refs).

Fischhoff, I.R., Sundaresan, S.R., Cordingley, J., Rubenstein, D.I., 2007. Habitat use and movements of plains zebra (Equus burchelli) in response to predation danger from lions. Behav. Ecol. 18, 725-729.

Galanti, V., Preatoni, D., Martinoli, A., Wauters, L.A., Tosi, G., 2006. Space and habitat use of the African elephant in the Tarangire-Manyara ecosystem, Tanzania: implications for conservation. Mamm. Biol. - Zeitschrift für Säugetierkunde 71, 99-114.

Galwey, N.W., 2007. Beyond mixed modelling. Introduction to Mixed Modelling. John Wiley \& Sons, Ltd.pp. 213-214.

Godvik, I.M.R., Loe, L.E., Vik, J.O., Veiberg, V., Langvatn, R., Mysterud, A., 2009. Temporal scales, trade-offs, and functional responses in red deer habitat selection. Ecology 90, 699-710.

Graham, M.D., Douglas-Hamilton, I., Adams, W.M., Lee, P.C., 2009. The movement of African elephants in a human-dominated land-use mosaic. Anim. Conserv. 12, 445-455.

Hamel, S., Côté, S.D., 2007. Habitat use patterns in relation to escape terrain: are alpine ungulate females trading off better foraging sites for safety? Can. J. Zool. 85, 933-943.

Hart, B.L., Hart, L.A., Pinter-Wollman, N., 2008. Large brains and cognition: where do elephants fit in? Neurosci. Biobehav. Rev. 32, 86-98.

Helfman, G.S., 1989. Threat-sensitive predator avoidance in damselfish-trumpetfish interactions. Behav. Ecol. Sociobiol. 24, 47-58.

Ihwagi, F.W., Chira, R.M., Kironchi, G., Vollrath, F., Douglas-Hamilton, I., 2012. Rainfall pattern and nutrient content influences on African elephants' debarking behaviour in Samburu and Buffalo Springs National Reserves, Kenya. Afr. J. Ecol. 50, 152-159.

Ihwagi, F.W., Wang, T., Wittemyer, G., Skidmore, A.K., Toxopeus, A.G., Ngene, S., King, J., Worden, J., Omondi, P., Douglas-Hamilton, I., 2015. Using poaching levels and elephant distribution to assess the conservation efficacy of private, communal and government land in northern Kenya. PLoS One 10, e0139079.

Jachmann, H., 2013. Pilot study to validate PIKE-based inferences at the site level. Pachyderm 52, 72-87.

Kahindi, O., Wittemyer, G., King, J., Ihwagi, F., Omondi, P., Douglas-Hamilton, I., 2010 Employing participatory surveys to monitor the illegal killing of elephants across diverse land uses in Laikipia-Samburu, Kenya. Afr. J. Ecol. 48, 972-983.

Kitchen, A.M., Gese, E.M., Schauster, E.R., 2000. Changes in coyote activity patterns due to reduced exposure to human persecution. Can. J. Zool. 78, 853-857.

Levin, S.A., 1992. The problem of pattern and scale in ecology: the robert H. MacArthur award lecture. Ecology 73, 1943-1967.

MIKE, 2001. Report on the Meeting to Launch the Implementation of MIKE in West Africa. Ouagadougou, Burkina Faso 19-21 February 2001. MIKE.

Nellemann, C., Formo, R.K., Blanc, J., Skinner, D., Milliken, T., De Meulenaer, T., 2013. Elephants in the Dust -the African Elephant Crisis. A Rapid Response Assessment. United Nations Environment Programme, GRID-Arendal, Birkel and Trykkeri AS, pp. 80.

O'Donoghue, P., Rutz, C., 2016. Real-time anti-poaching tags could help prevent im minent species extinctions. J. Appl. Ecol. 53, 5-10.

Pastorini, J., Prasad, T., Leimgruber, P., Isler, K., Fernando, P., 2015. Elephant GPS tracking collars: is there a best? Gajah 43, 15-25.

Powell, R.A., Mitchell, M.S., 2012. What is a home range? J. Mammal. 93, 948-958.

R Development Core Team, 2012. R Foundation for Statistical Computing. R Development Core Team, Vienna, Austria.

Sanchez-Mercado, A., Ferrer-Paris, J.R., Yerena, E., Garcia-Rangel, S., Rodriguez-Clark, K.M., 2008. Factors affecting poaching risk to Vulnerable Andean bears Tremarctos ornatus in the Cordillera de Merida, Venezuela: space, parks and people. ORYX 42, 437-447.

Thouless, C.R., King, J., Kahumbu, P.G., Douglas-Hamilton, I., 2008. The Status of Kenya's Elephants 1990-2002. Kenya Wildlife Service, Nairobi, Kenya.

Tukey, J.W., 1977. Exploratory Data Analysis. Addison-Wesley, Reading, PA.

Vanak, A.T., Thaker, M., Slotow, R., 2010. Do fences create an edge-effect on the movement patterns of a highly mobile mega-herbivore? Biol. Conserv. 143, 2631-2637.

Wall, J., Wittemyer, G., Klinkenberg, B., LeMay, V., Douglas-Hamilton, I., 2013. Characterizing properties and drivers of long distance movements by elephants (Loxodonta africana) in the Gourma, Mali. Biol. Conserv. 157, 60-68.

Wall, J., Wittemyer, G., Klinkenberg, B., Douglas-Hamilton, I., 2014. Novel opportunities for wildlife conservation and research with real-time monitoring. Ecol. Appl. 24, 593-601.

Wittemyer, G., Daballen, D., Rasmussen, H., Kahindi, O., Douglas-Hamilton, I., 2005a. Demographic status of elephants in the Samburu and Buffalo Springs National Reserves, Kenya. Afr. J. Ecol. 43, 44-47.

Wittemyer, G., Douglas-Hamilton, I., Getz, W.M., 2005b. The socioecology of elephants: analysis of the process creating multitiered social structures. Anim. Behav. 69, 1357-1371 (tables; figs;refs).

Wittemyer, G., Daballen, D., Douglas-Hamilton, I., 2013. Comparative demography of an at-risk African elephant population. PLoS One 8, e53726.

Wittemyer, G., Northrup, J.M., Blanc, J., Douglas-Hamilton, I., Omondi, P., Burnham, K.P., 2014. Illegal killing for ivory drives global decline in African elephants. Proc. Natl. Acad. Sci. U. S. A. 111, 13117-13121.

Wittemyer, G., 2001. The elephant population of Samburu and Buffalo Springs National Reserves, Kenya. Afr. J. Ecol. 39, 357-365 (table;figs;map;refs).

Wyatt, J.R., Eltringham, S.K., 1974. The daily activity of the elephant in the Rwenzor National Park, Uganda. Afr. J. Ecol. 12, 273-289. 